\title{
Lavage or not to lavage - hazards due to deviation from National Guidelines
}

\author{
Naser K A ${ }^{1}$, Abeysekara R A ${ }^{2}$, Gawarammana I B ${ }^{2,3}$ \\ Journal of the Ceylon College of Physicians, 2018, 49, 22-24
}

\begin{abstract}
Self-poisoning with organophosphorus (OP) compounds has contributed to a large number of deaths in the developing world over many decades. While, most deaths are due to the inherent properties of the OP compounds, an important sub group of patients die due to iatrogenic causes, prevention of which will reduce death rates. In most developing countries, there is no continuous medical education of doctors who deliver primary care in rural villages which lead to iatrogenic deaths and disability.
\end{abstract}

We present two patients who presented unconscious to primary care units following ingestion of OP compounds. Both patients received gastric lavage by medically unqualified personnel, with unprotected airways and without informed consent. Both patients were transferred to a specialized unit with an unprotected airway and both aspirated gastric contents which lead to mechanical ventilation and prolonged hospital stay.

In both cases, the medical management deviated from accepted good clinical practice and National Guidelines.

Reducing deaths from pesticide self-poisoning would require a coordinated effort involving new antidote development and optimizing medical care given to these patients at both primary and tertiary care units. Minimizing iatrogenic causes of morbidity and mortality would require a

\footnotetext{
${ }^{1}$ Kings Mill Hospital, Mansfield, UK.

${ }^{2}$ Department of Clinical Medicine, Faculty of Medicine, University of Peradeniya, Sri Lanka.

${ }^{3}$ South Asian Clinical Toxicology Research Collaboration, Faculty of Medicine, University of Peradeniya, Sri Lanka.
}

Corresponding author: Naser K A

E-mail: mackanaser@gmail.com,
National approach at undergraduate and postgraduate levels. New mechanisms to improve knowledge of resuscitation, airway management and adherence to good clinical practice by primary care doctors should be initiated.

Key words: gastric lavage, aspiration, guidelines, poisoning

\section{Introduction}

Self-poisoning with pesticides is a major public health problem across the Asia Pacific Region ${ }^{1}$. It is estimated that globally $250-370,000$ people die from pesticide poisoning each year ${ }^{2}$. Sri Lanka has a major problem with intentional self-poisoning with high total and youth suicide rates ${ }^{3}$. To make matters worse $10-20 \%$ case fatality in the developing world differs markedly from the $0.5 \%$ found in the West which is mainly attributed to improvement of health care facilities as well as unavailability of toxic poisons in the West $^{4}$.

For much of the nineteenth century, gastric decontamination was routine in the management of patients with self-poisoning. Following an extensive review of the literature, the American and European academies of toxicology recommend that gastric lavage should not be employed routinely, if ever, in the management of poisoned patients and that the results of clinical studies in overdose patients weigh heavily on the side of showing a lack of beneficial effect ${ }^{5}$. Guidelines on gastric lavage published by the National Poisons Information Service clearly state that forced emesis should never be given to any patient and indications and contraindications to gastric lavage are clearly stated ${ }^{6}$. However, gastric lavage and forced emesis have become culturally ingrained as useful remedies in rural folk and it is not uncommon for relatives to request the doctors to perform lavage or forced emesis irrespective of the patient's clinical condition. Traditionally, the procedure is given by a group of nurses and untrained attendants. Further, in some Asian countries removal of gastric contents for medico-legal purposes is mandatory. Gastric lavage and forced emesis in unconscious and uncooperative patients can lead to adverse clinical outcomes ${ }^{5}$. 
We present two cases where deviations from National Guidelines in gastric decontamination led to adverse in hospital outcomes. We interviewed the doctors who were involved in the delivery of primary care of the two patients presented here.

\section{Case 1}

A male 32-years-old presented to a primary health care unit in a state of drowsiness sixty minutes following consumption of about $300 \mathrm{ml}$ of Dimethoate (organophosphorus compound (OPC)) under the influence of alcohol. Gastric lavage with a Ryle's nasogastric tube has been performed by an attendant and then transferred to a tertiary health care hospital after ninety minutes following ingestion. On admission patient had been unconscious with a blood pressure 120/70, pulse rate of 100 beats per minute (bpm) and clear lungs. Patient was given a repeat gastric lavage by the attending nursing officer followed by activated charcoal and then started on pralidoxime and atropine infusion. After three hours, patient was transferred to a specialised toxicology unit without intubation.

On admission the patient was drowsy (GCS 8/15), charcoal was seen coming out from nose and mouth, had bilateral lung crepitations, blood pressure was 120/ $70 \mathrm{mmHg}$, pulse rate $78 \mathrm{bpm}$. Soon afterwards the patient developed respiratory arrest and was intubated and ventilated. During intubation it was noted that charcoal was coming from the endotracheal tube. Patient required only two $0.6 \mathrm{mg}$ boluses of Atropine (total dose of $1.2 \mathrm{mg}$ ) to counteract cholinergic signs. During hospital stay he developed pneumonia and was discharged after 11 days.

\section{Case 2}

A male 34-years-old was admitted to a primary health care unit within five minutes of consuming about $100 \mathrm{ml}$ of chlorphyrifos (OPC). On admission patient had been under the influence of alcohol, drowsy (GCS $10 / 15)$, blood pressure $120 / 80 \mathrm{mmHg}$, pulse rate of $88 \mathrm{bpm}$ and with clear lungs. Induced vomiting had been done using one litre of salt water by an attendant, activated charcoal given and patient immediately transferred to a specialised toxicology unit after 90 minutes.

On admission to the toxicology unit, the patient was drowsy (GCS 8/15), had bilateral pin point pupils, blood pressure $110 / 70 \mathrm{mmHg}$, pulse rate 80 beats per minute, and there were bilateral lung crepitations with a peripheral Oxygen saturation of $85 \%$. During endotracheal intubation charcoal was seen to come out from the endotracheal tube. He required a bolus of
$2.4 \mathrm{mg}$ of atropine to counteract cholinergic signs. Due to the presence of lung crepitations atropine was given over 4 days (reducing infusions of $1.2 \mathrm{mg} /$ hour on day 1 and 2 , and $0.6 \mathrm{mg} /$ hour thereafter). Patient was extubated on day 4 but had to be re-intubated the following day due to hypoxia and ventilated for another two days. After eleven days patient was discharged home.

\section{Discussion}

Both patients had low Glasgow coma scale on admission to their respective local hospitals. Neither patient had the capacity to consent for the lavage. A doctor was not present during the procedure and there was no monitoring during the procedure. Both patients were given activated charcoal and transferred with an unprotected airway. Both patients aspirated gastric contents which led to a prolonged stay in hospital.

Their atropine requirements to counteract cholinergic signs were negligible compared to mean atropine doses (23.4mg (SD 22, range 1-75)) required in Sri Lanka ${ }^{7}$. Significant dimethoate ingestions lead to hypotension and death within 24 hours $^{8}$. These facts indicate that neither patient had taken significantly toxic doses and the prolonged hospital stay was due to iatrogenic aspiration of gastric contents.

National guidelines clearly state that gastric decontamination should be offered only to consenting and conscious patients with a protected air way with close monitoring under supervision of a doctor ${ }^{7}$. None of these pre-requisites were satisfied in these two patients. Furthermore, the procedure was carried out by medically unqualified personnel with limited knowledge of air way patency. The fact that both patients were transferred with a stomach full of charcoal indicates that the doctors too had limited knowledge of potential risks of aspiration.

Hazards of gastric lavage in the local setting has clearly been documented and a recent meta analysis found that there is no evidence of benefit from gastric lavage ${ }^{9,10}$. Despite these publications and guidelines by the National Poisons Information Centre, sub optimal practice of gastric lavage continues in the Island. The lack of adherence to good clinical practice is puzzling. It appears that there is a hindrance to transference of knowledge of good clinical practice to the hospitals where it matters most in Sri Lanka. For example, the Guideline was not available in one of the hospitals while none of the doctors in both hospitals have attended a continued medical education programme in managing self-poisoning or airway management. It is unfortunate that doctors in some developing countries like Sri 
Lanka do not require periodic accreditation to maintain up to date skill levels and knowledge. Doctors in peripheries work in isolation without supervision of consultants and research publications do not reach rural areas as internet access is not available and library facilities are not available.

Pesticide poisoning causes many deaths in Sri Lanka. Reducing deaths from pesticide self-poisoning would require a coordinated effort involving new antidote development and optimizing medical care given to these patients at both primary and tertiary care units. Minimizing iatrogenic causes of morbidity and mortality would require a National approach at undergraduate and postgraduate levels. New mechanisms to improve knowledge of resuscitation, airway management and adherence to good clinical practice by primary care doctors in Sri Lanka should be initiated.

\section{References}

1. Eddleston M, Phillips MR. Self-poisoning with pesticides. BMJ 2004; 328(7430): 42-4.

2. Gunnell D, Eddleston M, Phillips MR, Konradsen F. The global distribution of fatal pesticide self-poisoning: systematic review. BMC Public Health 2007; 7: 357.

3. World Health Organisation: World Health Report 2002. In:
Annex Table 2: death by cause, sex and mortality stratum in WHO Regions, estimated for 2001. World Health Organisation, Geneva, Switzerland.

4. Gunnell D, Eddleston M. Suicide by intentional ingestion of pesticides: a continuing tragedy in developing countries. Int J Epidemiol 2003; 32: 902-9.

5. American Academy of Clinical Toxicology and European Association of Poison Centres and Clinical Toxicologists. Position paper: gastric lavage. J Toxicol Clin Toxicol 2004; 42: 933-43.

6. Fernando R. Management of poisoning. The National Poisons Information Centre. $3^{\text {rd }}$ edition, 2007: 4-5.

7. Eddleston M, Buckley NA, Checketts $\mathrm{H}$, et al. Speed of initial atropinisation in significant organophosphorus pesticide poisoning - a systematic comparison of recommended regimens. J Toxicol Clin Toxicol. 2004; 42(6): 865-75.

8. Davies J, Roberts D, Eyer P, Buckley N, et al. Hypotension in severe dimethoate self-poisoning. Clinical Toxicoogy 2008; 46(9): 880-4.

9. Eddleston M, Haggalla S, Reginald K, et al. The Hazards of Gastric Lavage for Intentional Self-Poisoning in a resource Poor Location. Clinical Toxicology. 2007; 45(2): 136-43.

10. Yi Li, ML Tse, Gawarammana I, et al. Systematic review of controlled clinical trials of gastric lavage in acute organophosphorus pesticide poisoning. Clinical Toxicology 2009; 47(3): 179-92. 